\title{
A propósito de las actitudes y roles del antropólogo en su trabajo de campo ${ }^{1}$
}

\author{
NURIA FERNÁNDEZ MORENO \\ Departamento de Antropología Social y Cultural \\ UNED. Madrid
}

\section{RESUMEN}

El objetivo de este texto es analizar circunstancias determinantes en el trabajo de campo, que tienen que ver con las actitudes que el antropólogo mantiene con el grupo que estudia, prestando atención a algunos de los numerosos aspectos emocionales que comprende su vivencia. Estas reflexiones surgen del trabajo de campo que realicé en la isla de Bioko, en Guinea Ecuatorial, entre los años 1988 y 1992.

Palabras clave: Trabajo de campo, Métodơs ảntropológicos, Guinea Ecuatorial (Bioko), Observación participante.

\section{SUMMARY}

The main goal of this text is to analyze some determinant circumstamces doing fieldwork related to the attitudes maintained by the anthropologists among their group of study, payins attention to some of the various emotional aspects involved by doing it. These reflexions arose while carring out fieldwork among the Bubi en Bioko, Equatorial Guinea from 1988 to 1992.

Key words: Fieldwork, Anthropological Methods, Equatorial Guinea (Bioko), Participant Observation.

Mi intención en este texto no es otra que la de prestar atención a algunos de los numerosos aspectos emocionales que comprende la vivencia del trabajo de campo para el antropólogo y, en especial, la primera experiencia. Me interesa centrarme, concretamente, en las actitudes que mantenemos ante las situaciones que se van presentando, y cómo preci-

\footnotetext{
1 Tengo que agradecer a la profesora Eugenia Ramírez las numerosas sugerencias y matizaciones tan acertadas que me propuso a lo largo del texto, así como las discusiones tan fructíferas que mantuvimos a propósito del mismo.
}

RDTP, LVIII, 1 (2003): 153-170 
samente esta forma de "estar" y de "ser" de uno mismo puede condicionar el desarrollo de la investigación. Estas reflexiones son producto del trabajo de campo que realicé en la isla de Bioko, en Guinea Ecuatorial, entre los años 1988 y 1992.

El trabajo de campo supuso una iniciación para mí, puesto que fue el primero que realizaba prolongado e intensivo y también era la primera vez que vivía en el África Ecuatorial. Por tanto, es inevitable que toda la experiencia estuviera marcada por ese shock cultural que afecta a todos los ámbitos pero sobre todo al personal y, en consecuencia, también repercute en el trabajo. Al menos en estos contextos tan diferentes al propio creo que no se puede disociar el ámbito profesional del personal. El shock no se produce tanto por la extrañeza; lo que uno ve puede sorprenderle como si fuera un espectador, pero el antropólogo no lo es, así que el verdadero shock procede precisamente de que uno está inmerso en ese contexto tan diferente y debe reaccionar en él, interactuar con él y construir su nuevo entorno. La confrontación con algo tan radicalmente diferente a lo propio y cotidiano le transforma a uno; le obliga a hacer frente a los propios prejuicios, expectativas y fantasías de lo que uno se imaginaba que podía encontrarse.

El trabajo de campo que realicé consistía principalmente en el estudio del sistema de parentesco y el culto a los ancestros entre los bubis, que es la etnia autóctona de la isla de Bioko. El estudio trataba de explicar la diversidad de pautas culturales que encontramos actualmente en la organización del parentesco bubi, las transformaciones que ha sufrido y su relación con otras variables, como la evolución de las estrategias matrimoniales, las pautas de residencia y las relaciones internas de los clanes y linajes. El área de estudio se centró en seis poblados de la isla de Bioko con una población aproximada de unos 4900 habitantes que representa el 20\% de la población bubi. La distribución de estos poblados abarca, tanto asentamientos litorales, como del interior de montaña. Seleccioné una serie de poblados de diferentes dimensiones demográficas; algunos de ellos se encuentran ubicados en la provincia del norte, próximos a la capital y otros están muy aislados en la zona meridional. El período de tiempo que abarca el estudio transcurre a lo largo de unos sesenta años, desde los años veinte hasta principios de los noventa. La documentación existente y el trabajo con los informantes me han permitido remontarme hasta esas fechas. La articulación de los dos enfoques comparativos entre las variables espacio-temporales, es decir, entre las dos áreas geográficas y las generaciones, me planteó algunas dificultades, tanto metodológicas (debido a los numerosos puntos de estudio y a la variedad de fuentes de información que requerían) como analíticas: enlazar presente-pasado con la diversidad norte-sur. 


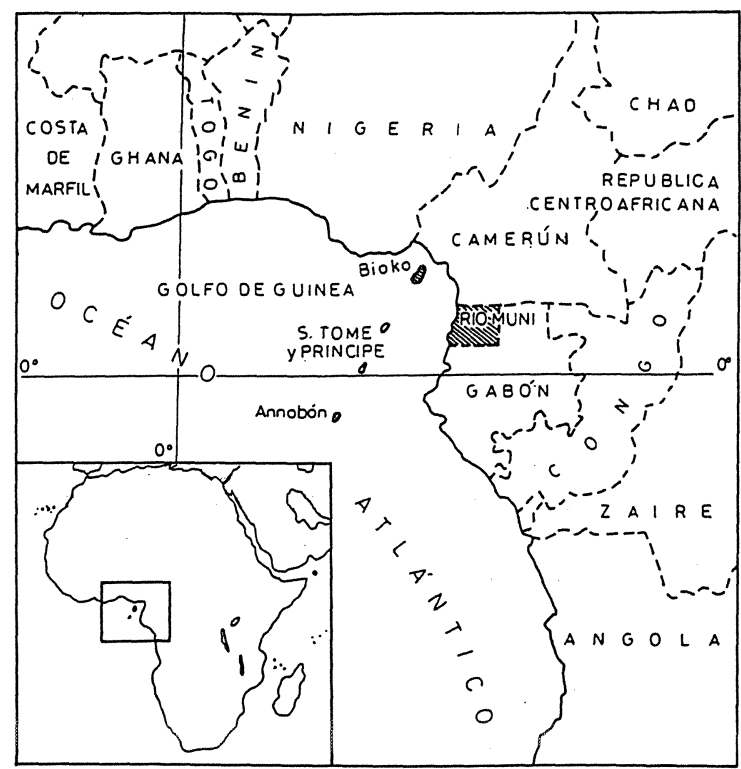

Figura 1.-La isla de Bioko está situada a sólo $32 \mathrm{~km}$ de la costa de Camerún y asentada sobre la plataforma continental.

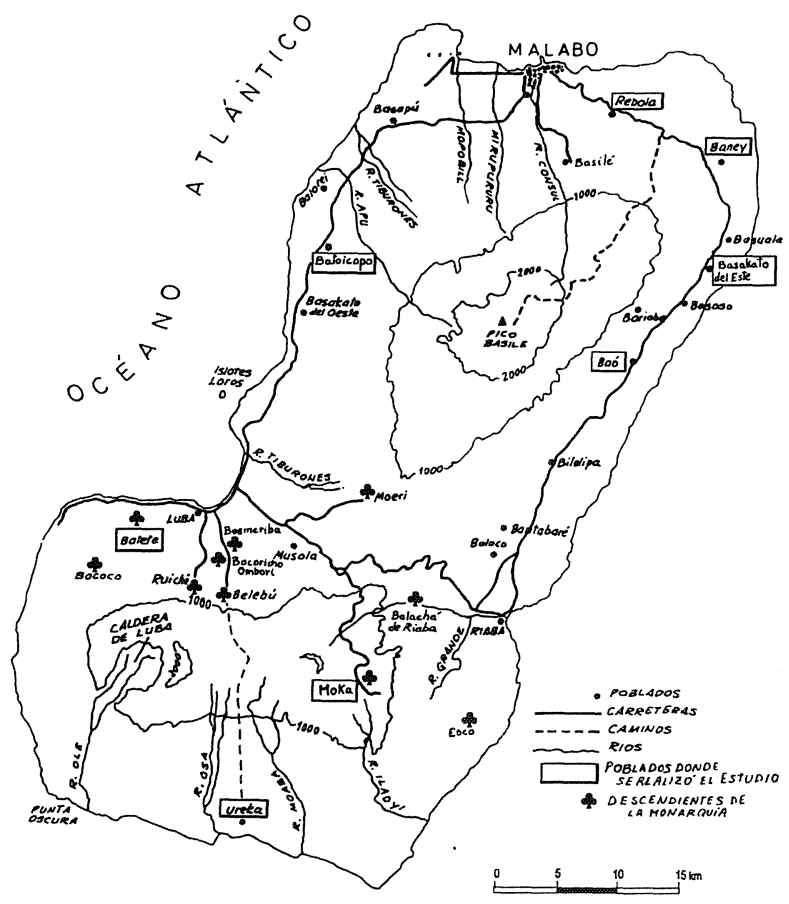

Figura 2.-Mapa de la Isla de Bioko. 
Además de estos problemas metodológicos y analíticos que fui encontrando a lo largo de la investigación, podría mencionar también los numerosos contratiempos coyunturales, propios de cada trabajo de campo y específicos de cada contexto, que desde luego, en Guinea Ecuatorial son considerables; o las dificultades posteriores durante la traducción y articulación de esa experiencia. Sin embargo, al margen de lo que para mí ha supuesto cada una de las etapas, la de empatía y la de distanciamiento con sus problemas puramente metodológicos, quisiera destacar algunos aspectos que me han sorprendido de la experiencia personal del trabajo de campo, quizá, como decía, por tratarse del primero. Cuestiones que en principio podrían considerarse como marginales. Me refiero, por un lado, a lo complejo que resulta el aprendizaje de los múltiples registros que requiere la interacción con los "otros", que al fin y al cabo es la esencia del trabajo de campo. Y, por otro, a la evolución que uno experimenta descle sus primeros momentos hasta el final del mismo; la cantidad de pretensiones con las que se comienza, las imposiciones que recibe y las que uno mismo se demanda. Esta idea de abordar la cara emocional de esta experiencia profesional, en especial al principio del proceso, y de las actitudes y posiciones que uno va tomando, me surgió ojeando el diario de campo y recordando muchas situaciones que en un principio, sin llegar a ser traumáticas, sí resultaban desagradables, incómodas y que en poco tiempo (a veces no tan poco) pasaban a ser triviales. Además, estas diferentes condiciones en las que uno se encuentra, en cierta medida, afectaban al proceso de obtención de información. De manera que la visión retrospectiva del diario me ha permitido darme cuenta de lo acertado o de lo equivocado de muchas actitudes y roles que se adoptan y desempeñan a lo largo de un trabajo de campo.

\section{EL ANTROPÓLOGO COMO SUJETO DE INICIACIÓN}

Me voy a referir al antropólogo como sujeto de iniciación durante ese proceso primero del trabajo de campo en el que se produce el encuentro y, a la vez, ya comienza la negociación entre uno mismo y los demás. Fn clefinitiva, se trata de abordar las estrategias que adopta el investigador para encontrar "su lugar" (lograr su integración) y la respuesta que

éstas generan. Por integración entiendo un estaclo en el que el antropólogo se encuentra ubicado y los demás también le han ubicado con sus cliferentes roles y estatus. Cuando se produce esta situación, es el momento en el que se puede iniciar el trabajo de campo porque se ha logrado, o al menos se tiene una sensación de haber conseguido, ser aceptado y 
saber desenvolverse suficientemente. Un factor que fue decisivo en mi caso para lograr esa aceptación y poder realizar el estudio que pretendía, fue la implicación de la comunidad bubi en general y sobre todo de los informantes. Esta implicación del sujeto estudiado en el trabajo de campo es fundamental. El hecho de querer conocer y estudiar la cultura de una etnia minoritaria, sometida y despreciada por la etnia mayoritaria que es la que gobierna el país, despertaba en ellos un interés por mi trabajo que favoreció la cooperación, no sólo por la competencia que pudieran tener como informantes, sino también por su enorme disponibilidad. La buena disposición que mostraban también rebajaba esa incómoda sensación de estar permanentemente en deuda con ellos.

La integración del investigador en otra comunidad extraña a la propia no depende exclusivamente de las estrategias, ni tampoco es cuestión de voluntades por ambas partes, sino que en buena parte se produce gracias a los "ritos iniciáticos implícitos" que el antropólogo experimenta. Estas iniciaciones se producen en situaciones como las que relataré más adelante que implicaban, por ejemplo, conocer los códigos de conducta a propósito de lo que es ofensivo, irrespetuoso o lo que es satisfactorio, o bien aprender normas de reciprocidad como la gratificación. Por último, me referiré a situaciones en las que la observación participante resulta un tanto paradójica. Situaciones todas ellas claves y recurrentes en los trabajos de campo y que, en muchas ocasiones, aprendemos con las iniciaciones que experimentamos, tanto en acontecimientos puntuales como durante las actividades cotidianas.

Califico estos ritos como implícitos en la medida que no están institucionalizados, no tienen una intencionalidad explícita, ni están preparados premeditadamente, es uno mismo quien los experimenta como tales. Asimismo, también caracterizo estas situaciones como ritos e iniciaciones y no simplemente como "pruebas" a las que se enfrenta el antropólogo como tantas otras personas lo hacen en sus respectivos trabajos o en multitud de acontecimientos cotidianos. Sin ánimo de trivializar la complejidad de los rituales de paso, menos aún de mitificar el trabajo de campo, y probablemente, en contra de la postura "anti-ritual" (dada la extensión que ha alcanzado el término ritual) que en su momento recomendó Goody (1977), creo que estas situaciones a las que me estoy refiriendo pueden incluirse dentro de las complejas categorías antropológicas de rito e iniciación.

En primer lugar, todo el trabajo de campo en conjunto que el antropólogo realiza por primera vez supone un rito de iniciación académica. Con la investigación que se deriva del mismo el antropólogo se estrena profesionalmente. Van Gennep (1986: 178) ya prestó atención al 
carácter ritual de "las primeras veces". En todas las sociedades existen momentos trascendentales para los individuos que tienen que ver con la importancia que se le concede a "la primera vez" y a las "entradas": los primeros alimentos que ingiere una criatura, los primeros dientes y primeros pasos; en unas culturas se concede gran importancia a la primera menstruación de una joven, en otras a las primeras relaciones sexuales, a la primera socialización: la entrada en el colegio, también el acceso a la universidad y por qué no el primer trabajo de campo del antropólogo.

En segundo lugar, a lo largo del proceso de trabajo de campo se producen, en particular, numerosas situaciones de iniciación, en especial durante su primera fase. Aunque estos ritos de la experiencia de campo a los que me estoy refiriendo no tienen un carácter formal, ni una estructura rígida, tampoco se trata de comportamientos simplemente rutinarios. Son experiencias que se asemejan bastante a los ritos de iniciación por las características que tienen, por lo que representan para la comunidad receptora y para el antropólogo. Son unas iniciaciones peculiares, puesto que no importa si se pasan satisfactoriamente o no, si uno es capaz o no de realizar una tarea determinada, de comer ciertos alimentos o de corresponder con la reciprocidad adecuada. Lo importante es afrontarlos porque no se evalúan las propias aptitudes, más bien se trata de una valoración de la persona. Puede que en estas situaciones no intervengan algunos de los elementos clásicos de las iniciaciones como el dolor, el acceso a grupos de edad, a sociedades secretas, de género, etc., pero sí aparecen otros temas característicos de las iniciaciones: las pruebas, novatadas y el acceso a "poder saber" y a "poder conocer". Aunque esa adquisición no sea la de un saber específico, supone el aprendizaje de una cultura nueva o de parte de la misma. A partir de este ejercicio de comunicación que implican estas acciones, se articula de otro modo la interacción entre el antropólogo y la comunidad. Es decir, estas iniciaciones pueden ser eficaces, ya que tienen consecuencias en las posteriores acciones y actitudes. Asimismo, los consideramos rituales porque se produce, aludiendo a las nociones introducidas por Van Gennep (1986), cierta transformación durante esa "transición" que experimentan las relaciones mutuas. Este autor, a quien debemos la terminología y el primer análisis de los ritos de paso, define estos ritos básicamente como un cambio de estado, un cambio de posición social. Considera que en las iniciaciones, que constituyen el prototipo de ritos de paso, siempre ocurren tres secuencias (separación, liminalidad y agregación) que marcan la transición de un estado a otro. En las situaciones por las que pasa el antropólogo en su trabajo de campo también experimenta una primera fase de separación o distanciamiento de su entorno y de su cultura, una segunda fase 
de marginalidad, de ambigüedad, de mezcla y una posterior de agregación, en la que ya tiene otra posición en la comunidad receptora. Se espera de él que haya adquirido al menos ciertos códigos y al tiempo que va perdiendo su inicial condición de "foráneo" va logrando su propio estatus.

Este tipo de iniciaciones, en comparación con otras más clásicas, presenta algunas peculiaridades. Por ejemplo, podemos decir que la fase liminal es casi permanente; el estado de "indeterminado", propio de los iniciados, es prácticamente la situación dominante del antropólogo durante todo el trabajo de campo. Las categorías de "ser" y "pertenecer" nunca llegan a completarse: ya no somos tan foráneos como en un principio pero nunca perteneceremos a su comunidad ni seremos como ellos. Como apuntan García, Velasco y otros (1991: 14): "ya no son lo que fueron y aún no son nada nuevo". Durante el trabajo de campo los antropólogos somos bastante "liminoides" - tomando prestado también un término que García, Velasco y otros (1991: 11) emplean al hablar de los procesos rituales. En definitiva, es lo que Turner (1988: 103) señala como mezcla de elementos que se dan en los fenómenos liminales: “...en estos ritos se nos ofrece un momento en y fuera del tiempo, dentro y fuera de la estructura social..." El antropólogo por su condición de extranjero o extraño a la comunidad, aunque en momentos puntuales esté "dentro de", no deja de estar "fuera de". Por lo que se refiere a la última de las fases que caracterizan estos ritos de iniciación, la de agregación, Van Gennep (1986: 36) define los ritos de paso del extranjero (a los que dedica un capítulo expresamente) como unos ritos característicos de agregación, por la analogía entre estas secuencias rituales y otros ritos de paso "clásicos". Habla de la compleja posición del extranjero y de toda una serie de ritos relativos a la forma de entrar en contacto, a la mutua aproximación. Todos ellos encaminados a "neutralizar" o normalizar la presencia del extranjero. Evidentemente, estos ritos no suponen una "agregación" inmediata pero, como trataré de ilustrar más adelante en los relatos, marcan un momento de. inicio para que aquélla se produzca gradualmente. A veces, son un requisito para empezar a entablar las relaciones y encontrarse algo más "ubicado" o "reubicado" en la comunidad.

Aunque estas iniciaciones se producen de forma casi continua en los comienzos, durante las primeras tomas de contacto son un proceso recurrente a lo largo del trabajo de campo porque se repiten cada vez que tratamos aspectos nuevos, cuando cambiamos de lugar, cada vez que se entablan nuevas relaciones, etc. Por otra parte, quiero resaltar que la iniciación del antropólogo, aunque resulte favorable para determinados aspectos, no significa que deba hacer un ejercicio de masoquismo heroico, como tantas veces se ha ensalzado o criticado. Es posible manejar estas 
situaciones de manera que se conviertan en algo productivo para nuestro aprendizaje de la otra cultura, sin que ello suponga un excesivo sacrificio; aunque en el momento en el que se nos presentan es bastante difícil relativizar la importancia que les adjudicamos.

Retomando el aspecto subjetivo-emocional que implican estas iniciaciones y el trabajo de campo en general, sorprende cómo en las etnografías se pormenoriza el modo cómo han sido recogidos los datos, los problemas metodológicos, las técnicas empleadas, etc., pero se tiene más pudor a la hora de exponer el trasfondo personal. Es decir: los condicionantes, las cludas o debilidacles, el agrado o desagrado que nos produce realizar ese trabajo y las consecuencias que tiene. Probablemente, estas cuestiones no reciben tanta atención porque parecen aspectos anecdóticos sin interés teórico ni interpretativo. Pero de hecho, la faceta de lo afectivo, emocional y subjetivo que implica esta experiencia influye en el propio desarrollo del trabajo de campo. Si del trabajo de campo se dice que uno de los conocimientos más importantes que se adquiere durante esta experiencia es el conocimiento de uno mismo, ¿por qué no analizar cómo ha sido ese proceso? En alguna ocasión, todos los antropólogos hemos relatado a los colegas o a los amigos algunas de aquellas experiencias relacionadas con esos momentos iniciales. Recordando algunos de ellos, quiero relatar situaciones que tienen que ver con la entrada del antropólogo en el grupo, con su ubicación y aceptación por parte de ellos, con el objeto de lograr esa meta de una convivencia estrecha y prolongada. Al margen de lo anecdótico, estas ocasiones me sirven para ilustrar precisamente esta otra faceta que forma parte de la investigación, así como para reflexionar sobre el aprendizaje del ejercicio del trabajo de campo. Éste también nos desvela facetas de uno mismo que hasta entonces no se habían puesto de manifiesto y, a veces, nos demuestra cómo uno es capaz, o no, de resolver y sustituir las carencias que se le presentan.

\section{COMER PARA IIACHR AMIGOS}

La siguiente anécdota está relacionada con lo que Van Gennep (1986) denominó la comensalidad. Comer y beber juntos constituye un rito típico de agregación, puesto que refuerza los vínculos ya existentes o los establece cuando se entablan relaciones:

Al cabo de, tan sólo, quince días de haber llegado a la isla de Bioko se me presentó la ocasión de acudir a la ceremonia de lo que llaman el bautizo tradicional del recién nacido. La ceremonia tenía lugar en un poblado en el que yo estaba 
muy interesada y donde deseaba instalarme porque era conocido por la pervivencia de las "tradiciones" bubis, un lugar clave en la cultura bubi. Conocí a una maestra que iba a bautizar a su nieta, me ofrecí para hacer el viaje en mi coche y ella me invitó a pasar una temporada en su casa. Nada más llegar comenzaron los preparativos del ágape. No presté la menor atención al resto de la ceremonia porque estaba horrorizada de enfrentarme al momento de la comida y de cómo iba a ser capaz de rechazar la invitación. Por ser la invitada me sirvieron la primera y la mejor parte. La comida principal en cuestión consistía en un enorme mono negro y peludo al que llaman satanás. La visión de aquel bicho antes de despellejarlo y trocearlo me recordó a mi perra que también era negra y lanuda, de la que por cierto me había costado bastante separarme y su recuerdo me venía con frecuencia. Llegado el momento, no fui capaz de rechazar la invitación. Me parecía que me hacían un honor y no debía corresponder con un gesto que yo entendía que podía resultar despectivo u ofensivo. Lo único que conseguí fue cambiar las piezas más preciadas que me sirvieron en un principio: la cabeza y una mano, por un muslito. Tengo que decir que, pasado el tiempo yo desayunaba sin problemas mono (cuando me quedaba sin galletas y leche condensada), eso sí al ajillo, con tomate o guisado de cualquier forma familiar para mí.

El hecho es que en aquel momento viví ese episodio con enorme desagrado y no como una invitación sino como un castigo, casi como una agresión (con independencia del gusto, me resultaba extremadamente difícil digerir algo tan parecido a mi perra). Para ellos, sin embargo, no era nada más que una oportunidad para tomar una comida de lujo, no suponía nada extraordinario, formaba parte de sus hábitos y, en ningún caso, aquello tenía que ver con una obligación iniciática hacia mí. Lo cual no significa que no estuvieran expectantes ante mi degustación. Estas situaciones que nos presentan aspectos de su vida cotidiana, ponen claramente de manifiesto, en especial por lo que se refiere a la "comensalidad", el carácter cultural no sólo de los hábitos alimenticios sino también de las categorías animales (comestibles versus mascotas) ${ }^{2}$. Lo que se produce en estas situaciones entre unos y otros, es una especie de empatía a la inversa: uno no se pone en el lugar del otro, sino que espera que sea el otro el que se ponga en su lugar. Ellos pueden pensar: "si ella fuera uno de nosotros le gustaría comer la mejor parte, la cabeza", y yo pensaba: "espero que entiendan que no me va a agradar demasiado comer la cabeza del mono". Creo que lo que me impulsaba a atribuirles "malas intenciones", a ponerme a prueba, no era más que mi propia impotencia por no ser capaz de hacerme con esa situación ni saber cómo salir de ella airosa. Todo esto tiene que ver con los estereotipos que atribuimos a los otros y que creemos que los otros nos atribuyen. Este-

${ }^{2}$ Leach (1993 [1965]) tiene un interesante artículo a propósito de la relación entre el lenguaje, la valoración social y ritual de los animales y su comestibilidad. 
reotipos que proceden de la ignorancia que es la que provoca inseguridad ante lo desconocido. Lo extraño y ajeno le hace a uno sentirse vulnerable, incapacitado o sumiso ante las sugerencias (que vive como iniciaciones) de los informantes o de la comunidad. Sólo a medida que se van conociendo los códigos de conducta es posible liberarse de ese "sometimiento del iniciado", lo cual también significa perder el miedo a nuestros propios prejuicios y estereotipos. Uno de los prejuicios más comunes derivado del desconocimiento de los códigos culturales ajenos es precisamente el temor a ofender al otro. Las reacciones de inseguridad que provoca el estar cohibido no sólo le pone a uno en una situación personal incómoda, sino que también repercute en el desarrollo del trabajo porque condiciona nuestra interacción: inhibe para hacer más preguntas, para grabar las conversaciones, fotografiar determinadas escenas, etc. Pero, además, ese temor a ofender o a transgredir las normas no responde sólo a tratar de evitar ser irrespetuoso, en el fondo también es una actitud instrumental e interesada por parte del investigador. Tememos que la reacción de malestar que pudiera provocar en los otros tenga consecuencias negativas para la investigación, dificulte las relaciones y perjudique nuestro trabajo y creemos que accediendo conseguimos una mayor empatía. ¿Qué es lo que esperan de uno? Esto es, en realidad, lo que nos mueve a mantener esas actitudes. El temor a ser etnocéntricos nos impide en ocasiones negarnos o expresar nuestra extrañeza de forma espontánea y entonces representamos (en el sentido más literal del proceso ritual), hacemos como si aquella situación nos fuera familiar. Sin embargo, a medida que pasa el tiempo, uno percibe que no pasa nada si se rechaza una invitación o una comida y en su lugar elige otra, o si nos expresamos con más naturalidad aunque cometamos faltas. Con bastante frecuencia olvidamos que el otro es mucho menos susceptible de ofenderse de lo que creemos.

\section{LA GRATIFICACIÓN: APRENDER A CORRESPONDER}

La segunda situación que planteo tiene que ver con lo complicado que resulta manejar las formas de corresponder con aquellos con los que pretendemos entablar una convivencia. Saber si es oportuno o no corresponder y si lo es, cuánto, cuándo y cómo se debe hacer; ¿qué concepto es el adecuado para cada situación? (regalos, favores, dinero, invitación) y ¿a quién se debe corresponder? El siguiente relato trata en definitiva de las normas de reciprocidad: 
Un mes después de mi primera estancia en el poblado, se celebraba otra ceremonia: una fiesta que conmemoraba la muerte del último rey bubi. Regresé al poblado para este evento y para instalarme ya de forma permanente allí. En esta ocasión iba a tener la oportunidad de conocer a todas las personas importantes que poseían un rango jerárquico destacado, bien por ostentar alguna jefatura de aldeas, bien por ser sacerdotes, etc. Entré en la cabaña acompañada de un informante que iría presentándome a toda aquella gente que allí dentro se congregaba. Previamente, me habían sugerido que llevara algún dinero en calidad de presente puesto que yo no sabía ni podía elaborar ninguna comida tradicional como ofrecía el resto de la gente. En previsión, me repartí distintas cantidades en los bolsillos del pantalón para no hacerme un lío con las monedas y los billetes en el momento preciso; de manera que pudiera entregarlo como corresponde según la categoría de cada persona. El interior de la cabaña estaba oscuro, había mucho humo y mucha gente. Mi acompañante me iba presentando: "esta señora ha venido como invitada y trae la ofrenda en señal de respeto porque está interesada en conocer nuestras tradiciones", "este papá [como llaman a los mayores] es el encargado de inaugurar la ceremonia..., éste de clausurarla..., éste es el sacerdote que invoca a los espíritus..." Yo iba entregando la "ofrenda" a unos y a otros con mucha pleitesía y con reverencias mutuas me iban dando las gracias. De repente, vislumbré al fondo un hombre sentado en un lugar central con las manos apoyadas en su bastón y en una actitud solemne. Evidentemente me había equivocado al pensar que el primero que me presentaron era el personaje principal. Aquél hombre era el más importante, el descendiente del último rey y a quien debía entregar la ofrenda. Pero ya no me quedaba nada de dinero. Me invadió un sentimiento de estar haciendo un ridículo espantoso.

La cuestión de la gratificación en el trabajo de campo parece ser un tema algo tabú, como si se tratara de un impuesto que el antropólogo debe pagar por ser un intruso, y no suele ser reconocido abiertamente por las críticas que suscita la información así obtenida. Evidentemente, no se trata de pagar por la información o de poner un precio a las entrevistas. Muchas veces, la transacción que se lleva a cabo es una forma de agradecer una invitación o la posibilidad que le ofrecen a uno de participar o de compartir, en definitiva, de ser acogido. En otras ocasiones, responde sencillamente a una de las posibles formas habituales de corresponder, pertenezca uno o no a la comunidad. Por otra parte, nadie tiene por qué ofrecer su tiempo y su espacio sólo porque uno quiera conocer sus costumbres, su cultura, y menos aún, con los estereotipos que a veces uno representa para la comunidad que le recibe. De manera que no podemos obviar el estatus que le atribuyen al observador. En Guinea Ecuatorial, por ejemplo, el europeo representa la opulencia, viene de la tierra de las oportunidades y es rico. Como en muchos otros lugares donde se llevan a cabo trabajo de campo, en Guinea Ecuatorial esto no es un estereotipo, es un hecho. Cualquier europeo tiene más o menos posibilidades de adquirir todo aquello que el guineano desea y 
no consigue. No me refiero a los recursos básicos para subsistir, sino a los medicamentos, hospitales, instrucción en las escuelas y a los bienes de lujo. Los informantes saben que si tenemos interés en realizar el trabajo de campo es porque obtenemos algún tipo de beneficio; el beneficio exige una reciprocidad y en todas las culturas existen formas de corresponder. El hecho es que en cualquier trabajo de campo en algún momento y de una forma u otra se corresponde con los informantes. El acuerdo al que se llegue en una situación puntual o como actitud general a lo largo de la investigación es una negociación personal entre el antropólogo y sus informantes.

\section{OBSERVAR Y PARTICIPAR PUEDEN SER INCOMPATIBLES}

If you are a successful participant observer you will know when to laugh at what your informants think is funny, and when informants laugh at what you say it will be because you meant it to be a joke (H. R. Bernard en Crabtree 1992: 45)

Por último, voy a referirme a la observación participante durante ese proceso inicial del trabajo de campo. La siguiente anécdota ilustra una escena bastante común para cualquier antropólogo durante el trabajo de campo. Me refiero a cuando el investigador se convierte en el sujeto observado:

Aquella presentación tan funesta que yo había tenido en la cabaña, ocurrió durante los preparativos para la fiesta conmemorativa que se celebraría al día siguiente. Esta ceremonia se iba a llevar a cabo en la zona del poblado que pertenece a la monarquía, en un patio que rodea a una de las casas. Durante aquella celebración la gente se agolpaba en un gran círculo alrededor de la ofrenda de comida. Puesto que podía presenciar el desarrollo de la ceremonia, yo ya estaba dispuesta a iniciar esa actividad clave en el trabajo de campo que es la observación participante. En un momento y sin saber cómo, me encontré en la paradójica situación de ser la persona más observada por todos los allí presentes (que era la mayor parte del poblado) y con menos capacidad de participar. Yo esperaba, como suele ser frecuente, que no me prestaran demasiada atención, de manera que pudiera presenciar el evento de forma discreta entre la multitud. Sin embargo, en respuesta a mi interés por compartir con los bubis sus fiestas, tuvieron la deferencia de invitarme no sólo a presenciarla sino a presidirla. En aquellos momentos, la sensación de ser el centro de atención no era una percepción subjetiva, era literal, pues me colocaron en el centro de aquel corro de gente, al lado de aquellos venerables mayores que ocupaban el lugar principal y rodeada de toda la multitud. Por requerimiento del jefe de poblado (que era quien me había introducido en el poblado y me había presentado a la gente) mi participación se limitó a explicar en un tono de voz bastante alto, debido al bullicio que había, las razones de mi estancia y mi intención de permanecer una temporada (en esos mo- 
mentos mi intención era la de salir de allí y empezaba a cuestionarme los motivos de estar realizando trabajo de campo). A partir de entonces, no fui capaz de prestar atención a nada de lo que acontecía, sólo quería que terminara cuanto antes.

En estas circunstancias, la posibilidad de la observación participante no se derivaba, como erróneamente yo tenía entendido, de un supuesto de aceptación e integración en la comunidad. Mi presencia e intervención, más que una invitación, parecía una exigencia por su parte. Esta participación obligada, donde no hay opción a sustraerse y donde el observador pasa a ser el observado, forma parte de la iniciación que la comunidad hace pasar implícitamente al antropólogo. Son pasos que a veces resultan necesarios para posteriormente poder entrar a formar parte de la comunidad, pasar algo más inadvertidos y, en el caso de la observación participante, poder participar luego de manera más espontánea. El hecho es que, al menos durante los primeros momentos del trabajo de campo, cuando retener y asimilar información es prioritario y, sobre todo, cuando el contraste cultural es tan acusado y hay que atender a tanta extrañeza, a mí me resultaba casi imposible combinar ambas actitudes: la de participar y observar a la vez.

La observación-participación es un proceso que llevamos a cabo continuamente en nuestra vida cotidiana y puede parecer demasiado simple para hacerlo consciente y sistematizarlo, sin embargo, como técnica de trabajo es útil hacerlo. No se trata de cuestionar las ventajas de esta técnica. La literatura antropológica nos presenta la observación participante como la regla de oro de la práctica de campo. A Malinowski le debemos esta forma peculiar y específica de la disciplina para recoger datos y generar conocimiento antropológico. Es indiscutible la importancia que se le concede y lo imprescindible que resulta. Muchos autores opinan, incluso, que todas las técnicas de investigación en el trabajo de campo dependen de la observación participante, pero no toda la observación participante es trabajo de campo ni todo el trabajo de campo debe hacerse a través de la observación participante. No es sólo una técnica que facilita la recogida de datos y proporciona un cuerpo amplio de información, es una estrategia de acceso a la comunidad para comprender su comportamiento. La principal ventaja que ofrece es la de proveernos del contexto cultural vivo sobre el que queremos saber. Pero creo que es útil aclarar la excesiva uniformidad y homogeneidad con la que a veces pretendemos emplear la observación participante. Puesto que existe una variedad de modos de participar y observar, se trata de redefinirlos y ver lo apropiados o no que resultan en cada momento. La observación participante implica una elección (de comportamientos), una adecuación obligada a cada contexto y a las etapas del trabajo de campo. 
Ha habido intentos de clasificar los roles que el antropólogo puede adoptar con esta técnica (Junker 1960): 1) el participante completo (cuando es miembro del grupo), 2) el participante como observador (opción que creo más adecuada en los primeros momentos), 3) el observador como participante (a la que nos referimos genéricamente como observación participante) o 4) el observador completo (cuando no tiene contacto con el grupo). Esta última opción es difícil de entender en el trabajo de campo. También se ha diferenciado entre: 1) observación sistematizada o abierta, 2) participación obligatoria, 3) participación-observación limitada y 4) observación privilegiada. Así mismo, desde las disciplinas de la psicología y sociología se han establecido categorías en cuanto a la participación del observador: 1) observación externa (cuando el investigador no pertenece al grupo y la observación no es participante ni sistemática) y 2) observación interna (cuando el investigador pertenece al grupo y la observación es sistemática). Esta última es equiparable a lo que en antropología entendemos por observación participante. Pero estas categorías son cuando menos discutibles, porque los contenidos que les adjudican no tienen por qué ser incompatibles. A grandes rasgos, yo diferenciaría dos modos principales de observación participante relacionados con el desarrollo del trabajo de campo, puesto que las formas de observación participante también dependen del proceso de adquisición de conocimiento como la propia investigación. De manera que cada una de estas formas de observar y participar son, por tanto, opciones según la etapa del trabajo de campo. La elección depende del propósito que se tenga o que a uno le permitan. A veces, uno no tiene opción de adoptar la modalidad que cree más adecuada; esto suele suceder con mayor frecuencia durante la primera etapa del trabajo de campo, en la que a veces uno es invitado a participar cuando no quiere y viceversa.

Así pues, durante una primera etapa, cuando todo resulta prácticamente desconocido, lo más idóneo sería observar de una forma no excesivamente sistemática y participar lo menos posible. De esta manera, podremos prestar toda la atención al conjunto, especialmente cuando la acción no es repetible. Durante esta etapa, la tendencia consistiría en tratar de observar todo para poder contextualizarlo y detectar los fenómenos. Posteriormente, podremos buscar su frecuencia, relevancia o no, por qué ocurren, etc. En esta fase se suele atender más a las acciones en detrimento de las relaciones porque éstas son más sutiles; es como si utilizáramos una lente de gran angular para fotografiar todo el campo, el paisaje, para después poder captar retratos en detalle.

Sin embargo, en una segunda etapa del trabajo de campo, cuando el antropólogo ya está más familiarizado, es posible combinar las dos activi- 
dades a la vez, del mismo modo que según vamos obteniendo más información se va adquiriendo mayor capacidad para interpretarla casi inmediatamente. La observación nos brinda la posibilidad de describir, de saber lo que hace el otro. Pero es la participación, la interacción, la que nos permite interpretar y saber cómo lo experimentan y qué es lo que piensan. En esta fase, la participación del investigador en la vida de los demás es más espontánea, ya no existe esa necesidad de actuar como uno de ellos porque el antropólogo es menos intruso, ahora tiene un lugar, un rol reconocible. Podemos decir que forma parte de la acción en escena con su propio guión. En estas condiciones, la observación ya no es tan panorámica, sino más selectiva, dirigida e intencionada y también se ha adquirido una mayor capacidad para decidir cuando intervenir o no. Esta posibilidad de participar voluntariamente sí podemos considerarla un indicio de integración, en el sentido de dominio del contexto. En esta fase uno está más capacitado para constatar la correspondencia entre lo que ocurre y lo que cree que ocurre. Por ejemplo, durante una escena cotidiana como puede ser el reparto del pescado capturado en una jornada, un observador extraño a la comunidad no percibe las estrategias que en ese momento se ponen en marcha. Sin embargo, cuando uno ya conoce a la población con sus redes de relaciones, esta escena de reparto de alimentos es sumamente reveladora de las normas de reciprocidad hacia parientes o amigos. No se entrega pescado a cualquiera que pase por alli, en estas acciones se premia, se corresponde, se castiga o se desprecia. De igual forma que la participación en una fase prematura del trabajo no facilita la recogida de datos, la observación inicial también puede resultar engañosa porque es difícil distinguir, por ejemplo, lo que es rutinario de lo que es excepcional. Recuerdo que durante las primeras ceremonias a que asistí, pensaba que el orden de repartir y tomar los alimentos o las piezas que se entregaban a cada persona tenía que ver con el hecho de tratarse de un acontecimiento extraordinario y de personas que en ese momento representaban un estatus determinado. Con el tiempo, me di cuenta, que a los hombres, tanto en las ceremonias como a diario, siempre se les reparte la comida antes que a las mujeres y son los que empiezan a comer primero. Las piezas que les servían, salvo algún hueso en particular u otras partes del animal que incluso pasaban más desapercibidas, tampoco tenían valor ritual alguno, simplemente respondían al gusto de cada uno. Muchas veces, aunque lo corroboren los informantes, resulta que la razón de ser del hecho en cuestión no se debe a lo que uno piensa sino que son coincidencias o que uno mismo no plantea la pregunta adecuada.

En definitiva, la observación participante consiste en tratar de experimentar y entender la vida de los informantes, lo cual no significa tratar 
de convertirse en uno más. La integración en la comunidad no implica tratar de ser como uno de ellos. Esta demanda sólo se produce al principio, y nuestro intento de ser como los otros debe ser sólo una representación temporal. No debemos olvidar que el objetivo de participar no es perder la identidad sino poder conocer, recoger información e interpretar. ¿Cómo se puede pretender pasar inadvertido cuando uno es lo más destacado del conjunto? Toda habilidad para intentarlo es nula en esos momentos. Cuando se produce esta forma de observación participante "obligada" se contradice buena parte de las cualidades y aptitudes que debe mantenerse como observador y no se cumple el principio básico de la observación participante: la presencia en escena pero sin perturbar el desarrollo. No sólo no se cumple (entre otras cosas porque es un supuesto ideal) sino que se invierte, ya que la propia presencia trastoca todo el desarrollo de las relaciones y acciones. Altera el curso de los acontecimientos porque se escenifica para el que viene de fuera. Aún así no debemos olvidar que es una situación puntual e intencionada. Posiblemente, para que la gente no cambie de actitud cuando los observamos, antes tenemos que dejarnos observar y conocer. El problema es saber el límite de esa concesión que tenemos que hacer.

Creo que es un error tratar de poner en práctica principios teóricos que son inapropiados al momento. Parece algo contradictorio que si el trabajo de campo implica una estancia prolongada y continuada, nos empeñemos en una observación participante precipitada y plena al principio en la cual todavía resulta difícil perfilar hacia dónde se dirige esa observación y qué tipo de interpretación y descripción permite. Se trata entonces de una combinación de ambas a lo largo del proceso de la investigación.

Como he tratado de ilustrar, el trabajo de campo es, entre otras muchas cosas, básicamente, un proceso durante el cual tratamos de familiarizarnos con la racionalidad del otro, con su realidad para poder comprenderla e interpretarla. Pero a lo largo de ese camino se pone de manifiesto lo limitado de nuestro bagaje con el que uno parte porque resulta imposible formarse y prepararse para aquello que es imprevisible. A lo sumo, lo que ponemos a prueba son los recursos con los que uno cuenta para afrontar lo imprevisible. Esto es en realidad lo que se aprende durante la experiencia del trabajo de campo. El trabajo de campo es un continuo proceso de evaluación personal y ajeno. Por ello, creo que es importante incluir, en el análisis y en las reflexiones a propósito de su 
metodología, las actitudes que mantiene y lo que experimenta el antropólogo.

Actitudes, que en algún momento, como sucede durante la etapa inicial, nos pueden conducir a un exceso de identificación con el otro para conseguir una mejor o más rápida adaptación al grupo, sometiéndonos a lo que uno experimenta como ritos de iniciación, más bien por temor a ser rechazados que por despojarse de los propios prejuicios. Bien al contrario de suponer esto una integración, implícitamente lo que resalta es la posición marginal que uno ocupa. Para invertir esta situación, como en otros ritos de iniciación, la transición del estatus (en este caso) de foráneo a conocido, está marcada por una intención y un énfasis explícito por eliminar las diferencias (se le exige y uno mismo se exige, tomar los mismos alimentos como si estuviera habituado a ellos, desempeñar las mismas tareas, presidir ceremonias, etc.). A partir de ese momento, una vez "iniciados" e "igualados", se restauran de nuevo las diferencias y las posiciones de cada uno, pero de otra forma, más integradas y aceptadas. Después de este proceso de ida y vuelta ya es posible y admisible expresar la conducta que esperan de uno en función de lo que uno representa y de su nueva ubicación en la comunidad. Es uno mismo quien puede acortar estos tránsitos, que son un "dar y tomar" la medida de cada cual. Este "posicionarse" ante los "otros" y el que los otros le sitúen a uno es una de las etapas más difíciles del trabajo de campo.

En este sentido, los ritos de iniciación del antropólogo son hasta cierto punto inevitables y a la vez necesarios para conocer a los demás, para que ellos nos conozcan y para conocernos a nosotros mismos un poco más. Pero ello no significa que sea indispensable sufrir, no implican un sacrificio si sabemos que lo decisivo es afrontarlos y que tanto aceptarlos como rechazarlos es una forma de hacerlo. Lo importante es ser conscientes de que las actitudes que adoptamos y adoptan unos y otros tienen consecuencias sobre las acciones y actitudes posteriores, sobre la percepción de uno mismo por los demás, sobre la confianza que nos brindan o que ofrecemos, etc. El sentimiento que en algunos momentos se tiene de estar sometido a los imperativos del trabajo de campo es algo bastante común, con independencia del contexto cultural en el que se lleve a cabo. Puesto que es una cuestión voluntaria, se debe estar alerta a los límites que queremos marcar, porque de lo que no cabe duda es de que el estado anímico del investigador influye en su producción intelectual. No se obtiene la misma información cuando uno está (durante demasiado tiempo) deprimido, harto de pasar calamidades, a disgusto..., que cuando uno está alegre, disfrutando y con ilusión. En este caso, el resultado de la experiencia personal es mucho más gratificante y esto, 
para mí, es tan importante como el resultado profesional que uno pueda ofrecer a los demás. La actitud que yo mantuve a partir de algún momento durante el trabajo de campo de sopesar qué tipo de exigencias eran convenientes o inútiles, en mi caso no fue una decisión racionalizada en el momento. Pero, afortunadamente, creo que fue acertada, porque el resultado, además de una etnografía, fue el de una experiencia positiva, enriquecedora y, sobre todo, divertida.

\section{BIBLIOGRAFÍA CITADA}

García, José L.; Honorio Velasco y otros. 1991. Rituales y proceso social. Estudio comparativo en cinco zonas españolas. Madrid: Ministerio de Cultura.

GENNEP, ARNOLD VAN. 1986. Los ritos de paso. Madrid: Taurus.

GOODY, JACK. 1977. "Against 'ritual': loosely structure thoughts on a loosely defined topic", en Moore y Myerhoff (eds.), Secular ritual: 25-35. Assem: Van Gorcum.

JUNKER, L. 1960. Fieldwork. Chicago: Chicago University Press.

LEACH, EDMUND. 1993. "Aspectos antropológicos del lenguaje: categorías animales e injuria verbal", en H. Velasco (ed.), Lecturas de antropología social. La cultura y las culturas: 265-292. Madrid: UNED. (ed. orig. 1965).

TURNER, VICTOR. 1988. El proceso ritual. Madrid: Taurus. 